\title{
A profile of anti-vaccination lobbying on the South African internet, 2011 - 2013
}

\author{
R J Burnett, ${ }^{1} \mathrm{MPH}, \mathrm{PhD}$; L J von Gogh, ${ }^{1} \mathrm{BA} ; \mathbf{M}$ H Moloi, ${ }^{2} \mathrm{MPH}$; G François, ${ }^{3} \mathrm{MSc}, \mathrm{PhD}$ \\ ${ }^{1}$ South African Vaccination and Immunisation Centre, Department of Virology, Sefako Makgatho Health Sciences University, \\ Pretoria, South Africa \\ ${ }^{2}$ Department of Public Health, Sefako Makgatho Health Sciences University, Pretoria, South Africa \\ ${ }^{3}$ Department of Epidemiology and Social Medicine, University of Antwerp, Belgium
}

Corresponding author: $R$ J Burnett (rose.burnett@smu.ac.za)

Background. The South African Vaccination and Immunisation Centre receives many requests to explain the validity of internet-based anti-vaccination claims. Previous global studies on internet-based anti-vaccination lobbying had not identified anti-vaccination web pages originating in South Africa (SA).

Objective. To characterise SA internet-based anti-vaccination lobbying.

Methods. In 2011, searches for anti-vaccination content were performed using Google, Yahoo and MSN-Bing, limited to English-language SA web pages. Content analysis was performed on web pages expressing anti-vaccination sentiment about infant vaccination. This was repeated in 2012 and 2013 using Google, with the first 700 web pages per search being analysed.

Results. Blogs/forums, articles and e-shops constituted $40.3 \%, 55.2 \%$ and $4.5 \%$ of web pages, respectively. Authors were lay people (63.5\%), complementary/alternative medicine (CAM) practitioners (23.1\%), medical professionals practising CAM (7.7\%) and medical professionals practising only allopathic medicine (5.8\%). Advertisements appeared on $55.2 \%$ of web pages. Of these, $67.6 \%$ were sponsored by or linked to organisations with financial interests in discrediting vaccines, with $80.0 \%$ and $24.0 \%$ of web pages sponsored by these organisations claiming respectively that vaccines are ineffective and that vaccination is profit driven. The vast majority of web pages (92.5\%) claimed that vaccines are not safe, and $77.6 \%$ of anti-vaccination claims originated from the USA.

Conclusion. South Africans are creating web pages or blogs for local anti-vaccination lobbying. Research is needed to understand what influence internet-based anti-vaccination lobbying has on the uptake of infant vaccination in SA.

S Afr Med J 2015;105(11):922-926. DOI:10.7196/SAMJ.2015.v105i11.9654

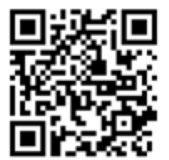

The South African Expanded Programme on Immunisation (EPI-SA) provides free universal infant vaccination against ten diseases, using an accelerated schedule for a programme that is unique in sub-Saharan Africa. ${ }^{[1]}$ Despite high EPI-SA administrative vaccination coverage figures (i.e. official District Health Information System data), reports of pockets of suboptimal vaccination coverage ${ }^{[2-4]}$ and sporadic measles outbreaks ${ }^{[2,3,5,6]}$ have prompted research into reasons why some SA children are not fully vaccinated. While an earlier survey of caregivers reported reasons such as missed vaccination opportunities, incorrect information given by clinic staff, unavailability of vaccines and lack of access to clinics, ${ }^{[4]}$ a more recent survey of EPI-SA managers reported that resistance from parents because of anti-vaccination rumours also plays a role. ${ }^{[3]}$ Anecdotal reports of parental refusal from SA healthcare workers support this finding. ${ }^{[2,6]}$

In addition, the South African Vaccination and Immunisation Centre (SAVIC) at the Sefako Makgatho Health Sciences University has received many requests from concerned parents to explain the validity of anti-vaccination claims found on the internet. These claims originated mainly from the USA, and previous global studies on internet-based anti-vaccination lobbying $^{[7-12]}$ had not identified any anti-vaccination web pages originating in SA. This seemed to suggest that while some SA parents are concerned about vaccination, this concern had not resulted in the creation of websites for local anti-vaccination lobbying. The aim of this study was therefore to characterise SA internet-based anti-vaccination lobbying.

\section{Methods}

During 2010, a pilot study identified search terms most likely to find SA anti-vaccination sentiment; these search terms were used for the first study in April 2011. Three search engines were used (Google, Yahoo and MSN-Bing), with searches limited to Englishlanguage (of the 11 official languages, this is the 'language of science' in $\mathrm{SA},{ }^{[7]}$ and all the researchers were proficient in English, with one being proficient in some of the other ten languages) SA web pages, and results with content referring to childhood vaccination being analysed for anti-vaccination sentiment. Web pages with medical advice about contraindications for specific vaccines were excluded. Duplicate web pages were discarded, and the remaining web pages were categorised as articles, blogs/forums or online shopping sites (e-shops). Detailed content analysis (anti-vaccination claims, author's profession, advertising content, country of origin of claim) was performed independently by two researchers, with consensus being reached for any discrepant findings. Data were captured in Microsoft Excel 2010 (Microsoft Office, USA) and imported into Epi Info version 3.5.3 (Centers for Disease Control and Prevention, USA) for quantitative analysis. In December 2012 and October 2013, the search was repeated using Google and the search term 'do not vaccinate, limited to English-language SA web pages. The exact phrase 'do not vaccinate' (identified in 2011 as returning the most hits) was tried as a search term in 2012, but fewer than 300 web pages were found, with very few being anti-vaccination. Google's 'advanced search' (discontinued during 2014) allowed for searches to include all words in a search string, and this identified a far greater number of anti-vaccination web pages. The later searches were therefore limited 
to web pages containing all words. The first 700 web pages of results were analysed independently by two researchers, with a third resolving any discrepant findings, and analyses were performed as in 2011. Web pages identified in 2011 and 2012 that were not among the first 700 hits in October 2013 and were still active were added to those found in October 2013 for the final analysis.

\section{Results \\ Anti-vaccination internet profile in April 2011}

The search terms identified by the pilot study (Table 1) found 238 web pages. Of these, $11.8 \%(28 / 238)$ contained anti-vaccination sentiment related to childhood vaccines. After discarding duplicates, 15 web pages remained for detailed content analysis. Of these, Google found 80.0\% (12/15) (Yahoo found 5 of these, 2 of which MSN-Bing also found; 7 were found by Google only), while Yahoo found 3 that were not found by Google or MSN-Bing.

Blogs/forums, articles and e-shops constituted $40.0 \%(6 / 15), 46.7 \%(7 / 15)$ and $13.3 \%$ $(2 / 15)$ of web pages, respectively. Of the blogs/ forums and articles, 50.0\% (3/6) and 14.3\% $(1 / 7)$, respectively, advertised products/ services provided by the author/sponsor promoting anti-vaccination claims, bringing the proportion of commercial web pages to $42.9 \%(6 / 15)$. Advertisements promoted natural health products $(16.7 \%, 1 / 6)$, a book about the dangers of mercury-containing dental fillings and a dental practice where mercury-containing fillings could be safely removed and replaced $(16.7 \%, 1 / 6)$ (antivaccination content on these web pages were related to the anti-vaccination claim that thimerosal, a mercury-based preservative used in multidose vaccines, results in idiopathic illnesses including autism), and products unrelated to anti-vaccination claims $(66.7 \%, 4 / 6)$.

Lay people constituted $66.7 \%(10 / 15)$ of the authors ( 7 parents, 2 journalists and 1 natural health product salesperson), $20.0 \%$ (3/15) were complementary/alternative medicine (CAM) professionals (an acupuncturist, a homeopath and an osteopath), and $13.3 \%(2 / 15)$ were medical professionals (a dentist and a doctor). Antivaccination claims included that vaccines are not safe $(93.3 \%, 14 / 15)$, that the risk of adverse events following immunisation (AEFIs) is higher than the risk of the disease $(73.3 \%, 11 / 15)$, that vaccination poses ethical/religious concerns $(40.0 \%, 6 / 15)$, that vaccines are ineffective $(33.3 \%, 5 / 15)$, that those promoting vaccination have financial motives $(33.3 \%, 5 / 15)$, and that vaccines were not responsible for the decline of infectious diseases $(26.7 \%, 4 / 15)$. The majority $(80.0 \%, 12 / 15)$ of the claims had links to web pages originating from the USA.

\section{Anti-vaccination internet profile in December 2012}

Of the first 700 web pages found using the term 'do not vaccinate', 37 contained antivaccination sentiment related to childhood vaccines. Blogs/forums, articles and e-shops constituted $40.5 \%$ (15/37), 54.1\% (20/37) and $5.4 \%(2 / 37)$ of the web pages, respectively. Of the blogs/forums and articles, $33.3 \%(5 / 15)$ and $60.0 \%(12 / 20)$, respectively, advertised products or services provided by the author/ sponsor promoting anti-vaccination claims, bringing the proportion of commercial web pages to $51.4 \%$ (19/37). Advertisements promoted natural health products $(63.2 \%$, $12 / 19)$, products unrelated to anti-vaccination claims $(21.1 \%, 4 / 19)$, a dental practice where mercury-containing fillings are 'safely' removed and replaced $(5.3 \%, 1 / 19)$, chelation products claiming to cure 'mercury toxicity' $(5.3 \%, 1 / 19)$, and a course on integrative medicine and a compact disc (CD) on the spiritual aspects of medicine (5.3\%, 1/19).

\begin{tabular}{l} 
Table 1 . List of search terms used for \\
the 2011 study \\
\hline Search terms (limited to the exact phrases) \\
\hline Do not immunise \\
Do not immunize \\
Do not vaccinate \\
Don't immunise \\
Don't immunize \\
Don't vaccinate \\
Immunisation is harmful \\
Not immunising \\
Not immunizing \\
Reasons for not vaccinating \\
Should not vaccinate \\
Vaccination is harmful \\
Vaccine injured \\
Vaccine scare \\
Vaccines are toxic
\end{tabular}

Table 2. Occupations of authors $(N=52)$ and advertising

\begin{tabular}{|c|c|c|}
\hline Author category & $n(\%)$ & $\begin{array}{l}\text { Adverts present } \\
n(\%)\end{array}$ \\
\hline Lay people ${ }^{\dagger}$ & $33(63.5)$ & $18(54.5)$ \\
\hline Parent $^{\ddagger}$ & $24(72.7)$ & $11(45.8)$ \\
\hline Journalist & $4(12.1)$ & $2(50.0)$ \\
\hline Attorney & $2(6.1)$ & $2(100.0)$ \\
\hline Business person & $2(6.1)$ & $2(100.0)$ \\
\hline 'Traditional Council'" & $1(3.0)$ & $1(100.0)$ \\
\hline CAM professionals & $12(23.1)$ & $10(83.3)$ \\
\hline Homeopath & $3(25.0)$ & $2(66.7)$ \\
\hline Naturopath & $5(41.7)$ & $5(100.0)$ \\
\hline Nutrition expert & $2(16.7)$ & $2(100.0)$ \\
\hline Craniosacral therapist & $1(8.3)$ & - \\
\hline Osteopath & $1(8.3)$ & $1(100.0)$ \\
\hline Medical professionals practising CAM & $4(7.7)$ & $2(50.0)$ \\
\hline Medical doctor (unspecified) practising homeopathy & $2(50.0)$ & $1(50.0)$ \\
\hline General medical practitioner practising homeopathy & $1(25.0)$ & $1(100.0)$ \\
\hline Medical doctor (unspecified) practising chiropracty & $1(25.0)$ & - \\
\hline Medical professionals & $3(5.8)$ & - \\
\hline Medical doctor (unspecified) & $1(33.3)$ & - \\
\hline Gastroenterologist & $1(33.3)$ & - \\
\hline Nurse & $1(33.3)$ & - \\
\hline \multicolumn{3}{|c|}{$\begin{array}{l}\text { *There were } 37 \text { web pages with advertising, but for } 7 \text { of these the authors could not be identified. } \\
\text { 'For the purposes of this study the term 'lay' refers to people who have not qualified as either medical (i.e. allopathic medicine) } \\
\text { or CAM practitioners. } \\
\text { "Parents who were also alternative medicine (1) or medical (1) professionals are not included here. } \\
\text { 'The same attorney wrote for both websites which were advertising the same dental practice. This dental practice advertised the } \\
\text { safe removal of dental fillings. } \\
\text { 'The KwaNgcolosi Traditional Council is a group of farmers/producers of Umlingo WamaNgcolosi, a juice that is claimed to } \\
\text { cure all diseases, including AIDS, although the group deny the existence of HIV/AIDS. }\end{array}$} \\
\hline
\end{tabular}


Of the authors who could be identified, $67.9 \%(19 / 28)$ were lay people (12 parents, 3 journalists, 2 natural health product salespeople, an attorney and a 'Traditional Council'), $21.4 \% \quad(6 / 28)$ were CAM practitioners (2 homeopaths, a homeopath practising as a natural birth expert, a craniosacral therapist, an osteopath and a nutrition expert), 7.1\% (2/28) were medical doctors practising CAM (a chiropractor and a homeopath), and $3.6 \%(1 / 28)$ was a medical doctor practising only allopathic medicine. Anti-vaccination claims were made about vaccine safety $(97.3 \%, 36 / 37)$, the risk of AEFIs $(83.8 \%, 31 / 37)$, vaccine effectiveness $(70.3 \%, 26 / 37)$, profit motives $(48.6 \%, 18 / 37)$, the decline of infectious diseases $(45.9 \%, 17 / 37)$, and ethical/religious concerns $(37.8 \%, 14 / 37)$. The claims had links to web pages originating from the USA $(81.1 \%, 30 / 37)$, the UK $(10.8 \%, 4 / 37)$ and India $(2.7 \%, 1 / 37)$.

\section{Anti-vaccination internet profile in October 2013}

Of the first 700 web pages found using the term 'do not vaccinate', 45 were identified as containing anti-vaccination sentiment related to childhood vaccines. Blogs/forums, articles and e-shops constituted $33.3 \%$ (15/45), 64.4\% (29/45) and 2.2\% (1/45) of the webpages, respectively. Of the blogs/ forums and articles, $26.7 \%(4 / 15)$ and $62.1 \%$ (18/29), respectively, advertised products or services provided by the author/sponsor promoting anti-vaccination claims, bringing the proportion of commercial web pages to $51.1 \%$ (23/45). Advertisements promoted natural health products $(65.2 \%, 15 / 23)$, products unrelated to anti-vaccination claims $(13.0 \%, 3 / 23)$, dental practices where mercury-containing fillings are 'safely' removed and replaced $(8.7 \%, 2 / 23)$, books about anti-vaccination $(8.7 \%, 2 / 23)$, and professional services related to autism $(4.3 \%$, $1 / 23)$.

Of the authors who could be identified, $55.6 \%(20 / 36)$ were lay people (15 parents, 2 journalists, 2 attorneys and 'Traditional Council'), $27.8 \%(10 / 36)$ were CAM practitioners (5 naturopaths, 2 nutrition experts, a homeopath, a homeopath practising as a natural birth expert and a craniosacral therapist), 8.3\% (3/36) were medical doctors practising CAM (2 homeopaths and a chiropractor), and $8.3 \%(3 / 36)$ were medical professionals (a doctor (unspecified), a nurse and a gastroenterologist). Anti-vaccination claims were made about vaccine safety (93.3\%, 42/45), the risk of AEFIs $(71.1 \%$, $32 / 45)$, vaccine effectiveness $(66.7 \%, 30 / 45)$, the decline of infectious diseases $(51.1 \%$,

Table 3. Products/services advertised on web pages ${ }^{\star}(N=37)$ and authors of antivaccination content

\begin{tabular}{|c|c|c|}
\hline Product/service & $n(\%)$ & Authors of anti-vaccination content \\
\hline Natural immune boosters & $22(59.5)$ & $\begin{array}{l}7 \text { unidentified, } 5 \text { naturopaths, } 2 \text { salespersons, } 2 \\
\text { nutrition experts, } 2 \text { mothers, } 1 \text { each homeopath, } \\
\text { osteopath, 'Traditional Council', journalist }\end{array}$ \\
\hline Unrelated to anti-vaccination & $8(21.6)$ & 7 mothers, 1 journalist \\
\hline Anti-vaccination books & $2(5.4)$ & Parents \\
\hline Dental filling replacement & $2(5.4)$ & $\begin{array}{l}\text { The same attorney wrote content on two } \\
\text { different websites }\end{array}$ \\
\hline Chelation products & $1(2.7)$ & Homeopath \\
\hline Course and $\mathrm{CD}^{\dagger}$ & $1(2.7)$ & Medical doctor practising as a homeopath \\
\hline Autism treatment & $1(2.7)$ & $\begin{array}{l}\text { General medical practitioner practising as a } \\
\text { homeopath }\end{array}$ \\
\hline
\end{tabular}

Table 4. Frequency of anti-vaccination claims on $67 \mathrm{SA}$ web pages

\begin{tabular}{ll}
\hline Anti-vaccination claim & $\boldsymbol{n}(\%)$ \\
\hline Vaccines are not safe & $62(92.5)$ \\
Risk of AEFIs greater than risk of disease & $49(73.1)$ \\
Vaccines are ineffective & $44(65.7)$ \\
Vaccines not responsible for decline in diseases & $32(47.8)$ \\
Vaccination poses ethical or religious concerns & $29(43.3)$ \\
Vaccination is profit driven & $27(40.3)$
\end{tabular}

$23 / 45)$, ethical/religious concerns $(46.7 \%$, $21 / 45$ ), and profit motives $(35.6 \%, 16 / 45)$. The claims had links to web pages originating from the USA $(73.3 \%, 33 / 45)$, the UK $(11.1 \%$, $5 / 45)$ and India $(2.2 \%, 1 / 45)$.

\section{Final analysis}

Twenty-two web pages identified in 2011 and 2012 were not among the first 700 hits in October 2013 but were still active, giving a total of 67 web pages for the final analysis. Blogs/forums, articles and e-shops constituted $40.3 \%$ (27/67), 55.2\% $(37 / 67)$ and $4.5 \%(3 / 67)$ of the web pages, respectively. The occupation of $77.6 \%$ $(52 / 67)$ of the authors could be identified (Table 2). Advertisements for products/ services provided by the author/sponsor promoting anti-vaccination claims were found on $55.2 \%(37 / 67)$ of the web pages (Table 3). Of these, $67.6 \%(25 / 37)$ were sponsored by or linked to organisations with financial interests in discrediting vaccines (selling products/services to build the immune system naturally $(88.0 \%)$ and to remove metals $(12.0 \%)$ ), with $80.0 \%$ $(20 / 25)$ and $24.0 \%(6 / 25)$ of web pages sponsored by these organisations claiming respectively that vaccines are ineffective and vaccination is profit driven. Of all

$\begin{aligned} & \text { Table 5. Countries of origin of anti- } \\
& \text { vaccination claims }(\boldsymbol{N = 6 7 )}\end{aligned}$
\begin{tabular}{ll}
\hline Country & $\boldsymbol{n}(\%)$ \\
\hline USA only & $48(71.6)$ \\
UK only & $1(1.5)$ \\
USA and UK & $4(6.0)$ \\
India & $2(3.0)$ \\
South Africa & \\
${ }^{*}$ No links to source provided. & $12(17.9)$ \\
\end{tabular}

commercial web pages, $32.4 \%(12 / 37)$ claimed that vaccination is profit driven. The vast majority of web pages claimed that vaccines are not safe (Table 4), with the majority of anti-vaccination claims originating from the USA (Table 5).

\section{Discussion \\ The profit motive behind anti- vaccination lobbying}

This study investigated anti-vaccination lobbying on SA web pages over 3 years. During piloting many anti-vaccination web pages contained advertisements for so-called natural alternatives to vaccines, or to treat the so-called 'vaccine-injured' child. Professions of authors, whether they or their 
sponsors advertised products/services, and web page type used as the platform for anti-vaccination lobbying, were therefore investigated.

Website articles and blogs/forums constituted the two largest platforms throughout the 3 years, while e-shops constituted the smallest platform. However, the proportion of commercial web pages increased every year, making up $55.2 \%$ in the final analysis. More importantly, $67.6 \%$ of commercial web pages were sponsored by organisations with financial interests in discrediting vaccines. Ironically, $80.0 \%$ of these web pages claimed that vaccines are ineffective, while selling products/services with no evidence of preventing vaccine-preventable diseases or curing the 'harms caused by vaccines'. Another irony is that $24.0 \%$ claimed that vaccination is profit driven, while their sponsors work in an industry that in 2009 had a global retail market worth EUR 45 - 50 billion (USD 61 - 68 billion), ${ }^{[13]}$ compared with the global vaccine market, which was worth only USD 24 billion in 2013. ${ }^{[14]}$

Lay people (mostly parents) constituted the largest proportion of authors, with just over half of their web pages containing advertisements. CAM practitioners were the next largest group, with over $80 \%$ of their web pages in the final analysis being commercial. Medical practitioners were the smallest group, with the web pages of those practising only allopathic medicine containing no advertisements, while half the web pages of medical doctors practising CAM contained advertising. Overall, CAM practitioners therefore advertised products/services more frequently than other groups.

Previous studies have reported on products being sold by those engaging in internet-based anti-vaccination lobbying, with $44 \%$ containing advertising, ${ }^{[15]}$ between $33 \%^{[11]}$ and $40 \%{ }^{[9]}$ selling antivaccination books, tapes and CDs, and between $13 \%^{[12]}$ and $16 \%^{[11]}$ selling natural products. While these figures are lower than those reported here, this does not imply that SA anti-vaccination lobbyists are profiting more from discrediting vaccines than those in other countries. No internet-based study can possibly identify all web pages containing anti-vaccination sentiment, and none of these studies attempted to do so. A probable explanation for commercial web pages being so well represented in all studies is that codes written in html (called meta tags, which are not visible in the web page text) are added to more sophisticated web pages to ensure that they are among the first 'hits' when searching using specific terms corresponding with the meta tags. ${ }^{[16]}$ Those who make a living out of selling products/services clearly benefit from increased visibility, and would be more likely to use meta tags than those who are not selling products/services.

Also, anti-vaccination lobbying in countries such as the USA is very well orchestrated by a number of sophisticated organisations with websites that often appear official and authoritative. ${ }^{[10,12,15]}$ Because of their apparent credibility, links to these websites abound on anti-vaccination web pages from all around the globe, and the more incoming links to a website, the higher this website is ranked when searching with Google. ${ }^{[16]}$ This phenomenon together with the use of meta tagging is probably the reason behind why these websites appear so frequently in global studies. Anti-vaccination organisations of this type do not seem to exist in SA, so it follows that commercial anti-vaccination web pages have a greater opportunity to rise to the top of the list of web pages found when searches are limited to SA web pages.

\section{Anti-vaccination claims and origins}

The original impetus for doing this study was that a number of SA parents had become concerned about vaccinating their children after reading anti-vaccination claims on the internet. At that time nothing was known about anti-vaccination lobbying on SA web pages, and most of the original claims brought to SAVIC originated from the USA. This study found that this is still the case, with most anti-vaccination claims in the final analysis originating from the USA, and not differing substantially from other global studies. For example, the finding in each year of the study that more than $90 \%$ of anti-vaccination web pages claimed that vaccines are not safe concurs with the $91-100 \%$ reported globally, ${ }^{[8-12]}$ with a more recent study reporting $80 \% .{ }^{[15]}$ Similarly, the finding that over $70 \%$ of anti-vaccination web pages in all years claimed that the risk of AEFIs is high is supported by the $76-100 \%$ reported globally. ${ }^{[8-12,15]}$ Interestingly, the claim that vaccines are ineffective was found on $33.3 \%$ of the 2011 SA web pages, and this finding is supported by the $32 \%$ found in a 2010 global study. ${ }^{[15]}$ However, by 2012 this had risen to $70 \%$, and in the final analysis $65.7 \%$ of SA anti-vaccination web pages made this claim, which is closer to earlier global reports of 79 $83 \% .{ }^{[9-11]}$ This gives support to the notion that SA anti-vaccination lobbyists are still in the process of catching up with global trends, ${ }^{[2]}$ and in future we may see this claim occurring more frequently. Other claims made on SA anti-vaccination web pages that did not appear as frequently as reported globally include that vaccination is profit driven $\left(40.3 \%\right.$ v. $52-91 \%$ globally $\left.{ }^{[9,10,12,15]}\right)$ and poses ethical/ religious concerns $\left(43.3 \%\right.$ v. $70-79 \%$ globally, ${ }^{[9-12]}$ with one study reporting $\left.44 \%^{[15]}\right)$. A possible explanation for the profit-motive claim being less frequent on SA web pages may be that so many of the anti-vaccination authors were themselves motivated by profit. While the irony of claiming that vaccination is profit driven while profiting from selling alternative products has already been pointed out, only $24 \%$ of those benefiting financially from discrediting vaccines made this claim. It is therefore possible that the other $76 \%$ recognised the hypocrisy of making this claim, and therefore avoided doing so. The lower frequency of ethical/religious concerns on SA web pages is perhaps easier to explain, since in SA vaccination is not mandatory, while in the USA it is. Violation of civil liberties is therefore irrelevant for South Africans who choose to not have their children vaccinated.

\section{Study limitations}

The 2011 study was limited by specific search terms identified in a pilot study as most likely to find anti-vaccination sentiment, and found that $11.8 \%$ of identified web pages had anti-vaccination content. In contrast, the 2012 and 2013 studies used a broader search term identifying greater numbers of web pages, the totals of which were not recorded, the first 700 web pages being analysed each year. However, the same search conducted in July 2014 found 7990 results, so these two samples conceivably represent about $10 \%$ of all web pages found each year. Because of the differing search terms, the 2011 findings may not be a valid baseline for those from 2012 and 2013. Also, because only the top 700 web pages were analysed, the 2012 and 2013 samples are not representative of antivaccination lobbying on the SA internet. However, this was not the intention of this study, which focused on the profile of those who are so interested in discrediting vaccines that they spend time and money on creating websites or blogs to do so. Finally, the study was limited to English-language web pages. There may therefore be SA anti-vaccination web pages in any of the other ten official languages, which may express different anti-vaccination concerns from those reported here. However, in September 2014 searches on words for vaccinate (or words used for vaccinate in languages with no word for vaccinate) found no relevant web pages. These words included ukugoma (isiZulu), kugoma (SiSwati), go thlabela (Sepedi), ukugonyal ukutofa (isiXhosa), inent (Afrikaans), ho kgahla/ho enta (Sesotho) and go enta (Setswana). 


\section{Conclusions}

The latest SA census (October 2011) found that 35.2\% of inhabitants have access to the internet, ${ }^{[17]}$ a substantial increase from the $15 \%$ reported in $2007 .{ }^{[18]}$ In the USA, where $81 \%$ of adults use the internet, $72 \%$ of internet users search for health information online. ${ }^{[19]}$ Of these, $77 \%$ start their search using a search engine (Google, Yahoo or Bing), 13\% use a health information specialist website such as WebMD, $2 \%$ use a general site such as Wikipedia, and only $1 \%$ use social media such as Facebook. ${ }^{[19]}$ Web pages sourced through search engines are therefore an important source of health information for most internet users in the USA. There are no data from SA on online health information-seeking behaviour. However, this study found that some South Africans have created web pages for local anti-vaccination lobbying, with many having financial interests in discrediting vaccines, and that they have taken their misinformation from web pages largely originating in the USA. Many of these anti-vaccination lobbyists are parents, so it is possible that a growing number of young SA parents are using a search engine such as Google to find information about vaccination, and are encountering misinformation instead. Now that the existence of SA internet-based anti-vaccination lobbying has been established, research is needed to understand what influence this has on the uptake of infant vaccination in SA.

Acknowledgements. The authors thank E A Tshatsinde and N G Burnett for validating the data.

Conflicts of interest. The salaries of SAVIC staff are funded by the Sefako Makgatho Health Sciences University. SAVIC also receives unrestricted educational grants from the vaccine industry for community projects.

\section{References}

1. South African Department of Health. Expanded Programme on Immunisation - EPI (SA) Revised Childhood Immunisation Schedule from April 2009. http://www.kznhealth.gov.za/vaccinations.pd (accessed 26 March 2015).

2. Burnett RJ, Larson $\mathrm{HJ}$, Moloi MH, et al. Addressing public questioning and concerns about vaccination in South Africa: A guide for healthcare workers. Vaccine 2012;30(Suppl 3):C72-C78. [http://dx.doi. org/10.1016/j.vaccine.2012.03.037]

3. Wiysonge CS, Ngcobo NJ Jeena PM, et al. Advances in childhood immunisation in South Africa: Where to now? Programme managers' views and evidence from systematic reviews. BMC Public Health 2012;12:578. [http://dx.doi.org/10.1186/1471-2458-12-578]

4. Corrigall I, Coetzee D, Cameron N. Is the Western Cape at risk of an outbreak of preventable childhood Corrigall J, Coetzee D, Cameron N. Is the Western Cape at risk of an outbreak of preventable child
diseases? Lessons from an evaluation of routine immunisation coverage. S Afr Med J 2008;98(1):41-45.

Le Roux DM, le Roux SM, Nuttall JJ, Eley BS. South African measles outbreak 2009 - 2010 as experienced by
L Le Roux DM, le Roux SM, Nuttall JJ, Eley BS. South African measles outbreat
a paediatric hospital. S Afr Med J 2012;102(9):760-764. [PMID: 22958701].

a paediatric hospital. S Afr Med J 2012;102(9):760-764. [PMID: 22958701].
Siegfried N, Wiysonge CS, Pienaar D. Too little, too late: Measles epidemic in South Africa. Lancet 6. Siegfried N, Wiysonge CS, Pienaar D. Too little, too late: Measles
2010;376(9736):160. [http://dx.doi.org/10.1016/S0140-6736(10)61100-2]

7. Webb P. Science education and literacy: Imperatives for the developed and developing world. Science 2010;328(5977):448-450. [http://dx.doi.org/10.1126/science.1182596]

8. Nasir L. Reconnoitering the antivaccination web sites: News from the front. J Fam Pract 2000;49(8):731-733. 9. Wolfe RM, Sharp LK, Lipsky MS. Content and design attributes of antivaccination web sites. JAMA 2002;287(24):3245-3248.

0. Davies P, Chapman S, Leask J. Antivaccination activists on the World Wide Web. Arch Dis Child 2002;87(1):22-25.

11. Zimmerman RK, Wolfe RM, Fox DE, et al. Vaccine criticism on the World Wide Web. J Med Internet Res 2005;7(2):e17.

12. Kata A. A postmodern Pandora's box: Anti-vaccination misinformation on the Internet. Vaccine 2010;28(7):1709-1716. [http://dx.doi.org/10.1016/j.vaccine.2009.12.022]

13. Brookes G. Economic Impact Assessment of the European Union (EU)'s Nutrition \& Health Claims Brookes G. Economic Impact Assessment of the European Union (EU)'s Nutrition \& Health Claims
Regulation on the EU food supplement sector and market. 2010. http://www.pgeconomics.co.uk/pdf/ Impact-Assessment-health-claims.pdf (accessed 26 March 2015).

14. World Health Organization. Prequalification to make high-quality, safe and affordable vaccines. 2013. http://www.who.int/features/2013/vaccine_prequalification/en/ (accessed 26 March 2015).

15. Bean SJ. Emerging and continuing trends in vaccine opposition website content. Vaccine 2011;29(10):1874-1880. [http://dx.doi.org/10.1016/j.vaccine.2011.01.003]

6. Wolfe RM, Sharp LK. Vaccination or immunization? The impact of search terms on the internet. Health Commun 2005;10(6):537-551

7. Statistics South Africa. Census 2011. https://www.statssa.gov.za/Census2011/Products/Census_2011 Key_results.pdf (accessed 26 March 2015).

18. Gillwald A, Moyo M, Stork C. Understanding what is happening in ICT in South Africa. Evidence for ICT Policy Action. Policy Paper 7, 2012. http://www.researchictafrica.net/docs/Policy\%20Paper\%20 $7 \% 20-\% 20$ Understanding $\% 20$ what $\% 20$ is $\% 20$ happening $\% 20$ in $\% 20$ ICT $\% 20$ in $\% 20$ South $\% 20$ Africa. pdf (accessed 26 March 2015)

19. Pew Research Center's Internet \& American Life Project. Health Online 2013. http://www.pewinternet. org/files/old-media//Files/Reports/PIP_HealthOnline.pdf (accessed 26 March 2015).

Accepted 4 August 2015. 